\title{
Influence of the Elevation of the Left Ventricular Diastolic Pressure on the Values of the First Temporal Derivative of the Ventricular Pressure (dP/dt)
}

\author{
Katashi Okoshi, José Roberto Fioretto, Rossano César Bonatto, Maria Teresinha Trovarelli Tornero, \\ Paulo José Ferreira Tucci \\ Botucatu, SP - Brazil
}

\begin{abstract}
Purpose-To assess the effects of the elevation of the left ventricular end-diastolic pressure (LVEDP) on the value of the $1^{\text {st }}$ temporal derivative of the ventricular pressure $(d P / d t)$.
\end{abstract}

Methods-Nineteen anesthetized dogs were studied. The dogs were mechanically ventilated and underwent thoracotomy with parasympathetic nervous system block. The LVEDP was controlled with the use of a perfusion circuit connected to the left atrium and adjusted to the height of a reservoir. The elevation of the LVEDP was achieved by a sudden increase in the height of a reservoir filled with blood. Continuous recordings of the electrocardiogram, the aortic and ventricular pressures and the $d P / d t$ were performed.

Results - Elevation of the LVEDP did not result in any variation of the heart rate $(167 \pm 16.0 \mathrm{bpm}$, before the procedure; $167 \pm 15.5 \mathrm{bpm}$, after the procedure). All the other variables assessed, including systolic blood pressure (128 $18.3 \mathrm{mmHg}$ and $150 \pm 21.5 \mathrm{mmHg})$, diastolic blood pressure $(98 \pm 16.9 \mathrm{mmHg}$ and $115 \pm 19.8 \mathrm{mmHg}), \mathrm{LVEDP}$ (5.5 \pm 2.49 and $9.3 \pm 3.60 \mathrm{mmHg})$, and $d P / d t(4,855 \pm 1,082$ $\mathrm{mmHg} / \mathrm{s}$ and $5,149 \pm 1,242 \mathrm{~mm} \mathrm{Hg} / \mathrm{s})$ showed significant increases following the expansion of the ventricular cavity. Although the elevation of the dP/dt was statistically significant, 6 dogs curiously showed a decrease in the values of $d P / d t$.

Conclusion-Sudden elevation of the LVEDP resulted in increased values of $d P / d t$; however, in some dogs, this response was not uniform.

Key words: Frank-Starling mechanism, dP/dt, ventricular function

Faculdade de Medicina de Botucatu - UNESP

Mailing address: Katashi Okoshi - Faculdade de Medicina de Botucatu-UNESP Depto de Clínica Médica - Distrito de Rubião Jr, S/N - 18618-000 - Botucatu, SP - Brazil
The rate of change in pressure with time (dP/dt), usually known as the $1^{\text {st }}$ temporal derivative of ventricular pressure, is one of the parameters employed for the assessment of the left ventricular function.

In the 60's and 70's, the maximal values of $\mathrm{dP} / \mathrm{dt}(\mathrm{dP} /$ dtmax) were largely employed to assess the inotropic capacity of the heart ${ }^{1-4}$. From the studies conducted at that time, it was suggested that $\mathrm{dP} / \mathrm{dt}$ did not reliably reflect the inotropic state. The concept that finally prevailed was that $\mathrm{dP} / \mathrm{dtmax}$ had limited practical applications as an indicator of the inotropic capacity ${ }^{5}$. The major limitation ${ }^{6,7}$ was the lack of specificity of this parameter, since other factors, in addition to myocardial inotropic capacity, interfered with the maximal value of $\mathrm{dP} / \mathrm{dt}$. The factors capable of interfering with the values of the $\mathrm{dP} / \mathrm{dtmax}$ include: the afterload ${ }^{7,8}$, the preload ${ }^{9,10}$ and the presence of myocardial hypertrophy ${ }^{2,11}$.

The correct interpretation of the relationship between the degree of myocardial stretching (preload) and dP/dt is particularly complex. According to the most traditional version of the concepts related to ventricular function, the inotropic capacity of the heart and the variation of the performance of the heart as a result of change in the muscular length during rest (Frank-Starling mechanism) were considered independent myocardial characteristics. Yet, the influence of the Frank-Starling mechanism on dP/dtmax would not be related to changes in the inotropic capacity of the heart. For this reason, variations in the ventricular volume occurring during the evaluation of $\mathrm{dP} / \mathrm{dt}$ max would preclude an exact definition of the inotropic state.

Advances in the knowledge of the physiological basis of myocardial contraction make this traditional view questionable, currently allowing alternative explanations. More recent information ${ }^{12-17}$ about the subcellular adjustments involved in the relationship between the ventricular stretching during rest and the mechanical performance of the ventricles indicate that myocardial stretching interferes with the degree of activation of the contractile phenomenon, i.e., with myocardial contractility. The identification of 
a functional interaction between the Frank-Starling mechanism and myocardial contractility requires adequate concepts related to the validity of $\mathrm{dP} / \mathrm{dtmax}$ when evaluating the inotropic capacity of the heart in the presence of changes in the preload.

A number of authors have described a direct relationship between the increase of the ventricular volume and the values of $\mathrm{dP} / \mathrm{dt}^{1,18-20}$. Others ${ }^{3,21,22}$, however, report lack of association between both parameters. It should be underscored that these studies were conducted according to protocols that established a period of time for the stabilization of the preparation after elevation of the preload, thus allowing circulatory accommodation. Consequently, the direct relationship between the ventricular volume and $\mathrm{dP} /$ dt was influenced by the circulatory adjustment.

In a study conducted in our laboratory, using preparations of isolated canine hearts, we noted that the sudden ventricular dilation was invariably followed by an increase in the values of $\mathrm{dP} / \mathrm{dt}^{15}$. In this experiment, the behavior of $\mathrm{dP} / \mathrm{dt}$ was only indicative of the response of the heart to the expansion of the ventricular cavity. No similar protocol was conducted in canine hearts in situ.

Thus, the objective of this study was to assess the behavior of the values of $\mathrm{dP} / \mathrm{dtmax}$ after a sudden increase in the diastolic pressure of the left ventricle (LV) and to discuss these findings in light of the current concept relating myocardial stretching and myocardial contractility.

\section{Methods}

Nineteen dogs, weighing 19.6 $\pm 4.4 \mathrm{~kg}(\mathrm{x} \pm \mathrm{sd})$, were studied. The dogs were anesthetized with meperidine $(2.0 \mathrm{mg} / \mathrm{kg})$ intramuscularly combined with an intravenous mixture of chloralose $(60 \mathrm{mg} / \mathrm{kg}$ ) and urethane $(600 \mathrm{mg} / \mathrm{kg})$. After being anesthetized, the dogs were placed in the horizontal supine position, intubated and mechanically ventilated. Catheterization of the femoral vein was performed for drug administration and fluid replacement. Subsequently, a median thoracotomy with pericardiotomy was performed. A catheter(length: $4 \mathrm{~cm}$; internal diameter: $1.4 \mathrm{~mm}$ ) was inserted into the left ventricular cavity through puncture of the apex, and the extremity of another catheter, which was inserted through the femoral artery, was placed in the ascending aorta. The distal tips of these catheters were connected to Statham P23-ID transducers, which were coupled to amplifiers (1205 model, with VR-12 polygraph, Electronics for Medicine). In order to control the ventricular filling pressure, a perfusion circuit connected to the left auricle and to the external jugular veins was designed. The circuit (fig. 1) contained tubes, a reservoir with a level limiting system, a stick to sustain the reservoir, allowing its movement in the vertical direction, and a perfusion pump.

The pressures of the LV and the aorta, the $\mathrm{dP} / \mathrm{dt}$ and a bipolar lead of the electrocardiogram were continuously monitored. After the surgical procedures and administration of atropine $(0.5 \mathrm{mg} / \mathrm{kg}$ IV $)$, the preparation was allowed to rest for $30 \mathrm{~min}$ to reach stabilization. The reservoir

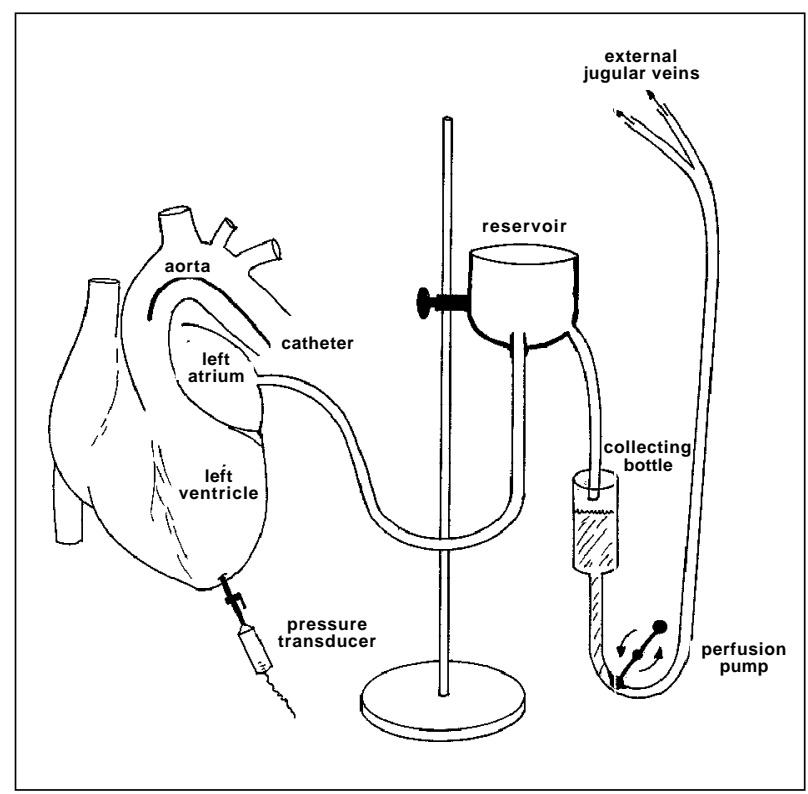

Fig. 1 - Schematic representation of the perfusion circuit used in the experiment.

was filled with blood and its height was adjusted so that the blood level in its interior corresponded to the left atrial pressure. During 10s of sustained expiratory apnea, the reservoir was suddenly elevated to promote a rapid increase in atrial pressure. These maneuvers enabled the recording of the ventricular and aortic pressures, as well as of $\mathrm{dP} / \mathrm{dt}$, in a control scenario and during the elevation of the ventricular filling pressure.

In order to assess the significance of the variations in the values of $\mathrm{dP} / \mathrm{dtmax}$, the Student $\mathrm{t}$ test for paired values was employed; when the differences whose probabilities depended on chance were $<5 \%(\mathrm{p}<0.05)$, they were considered statistically significant. To characterize the magnitude of the increase of the left ventricular end-diastolic pressure (LVEDP), of the systolic blood pressure (SBP) and of the diastolic blood pressure (DBP), $95 \%$ confidence intervals were constructed.

\section{Results}

The mean values and the standard deviations of the variables assessed in the control scenario and during the elevation of the LV dfiastolic pressure are exhibited in Table I. The heart rate did not show significant variation (167 \pm $16.0 \mathrm{bpm}$ and $167 \pm 15.5 \mathrm{bpm})$. In all dogs, increased values of SBP, DBP and LVEDP were observed. The SBP increased from $128 \pm 18.3 \mathrm{mmHg}$ to $150 \pm 21.5 \mathrm{mmHg}$, and the $95 \%$ confidence interval for the variation was $17.7-26.5 \mathrm{mmHg}$. The DBP increased from $98 \pm 16.9 \mathrm{mmHg}$ to $115 \pm 19.8 \mathrm{mmHg}$, and the $95 \%$ confidence interval for the variation was 12.9 $22.2 \mathrm{mmHg}$. TheLVEDP increased from $5.5 \pm 2.49 \mathrm{mmHg}$ to $9.3 \pm 3.60 \mathrm{mmHg}$, with a $95 \%$ confidence interval of 2.94 $4.64 \mathrm{mmHg}$ for the variation. In regard to $\mathrm{dP} / \mathrm{dtmax}$, there was an increase from $4,855 \pm 1,082 \mathrm{mmHg} / \mathrm{s}$ to $5,149 \pm 1,242 \mathrm{mmHg} /$ $\mathrm{s}$ and it was statistically significant $(\mathrm{p}=0.0169)$. The analysis 


\begin{tabular}{|lcc|}
\hline \multicolumn{2}{|c|}{$\begin{array}{c}\text { Table I - Hemodynamic data in the control scenario and during } \\
\text { elevation of the left ventricular diastolic pressure }\end{array}$} \\
\hline & Control & Elevation \\
\hline & $167 \pm 16.0$ & $167 \pm 15.5^{\text {ns }}$ \\
HR $(\mathrm{bpm})$ & $128 \pm 18.3$ & $150 \pm 21.5^{*}$ \\
$\mathrm{SBP}(\mathrm{mmHg})$ & $98 \pm 16.9$ & $115 \pm 19.8^{*}$ \\
$\mathrm{DBP}(\mathrm{mmHg})$ & $5.5 \pm 2.49$ & $9.3 \pm 3.60^{*}$ \\
$\mathrm{LVEDP}(\mathrm{mmHg})$ & $4,855 \pm 1,082$ & $5,149 \pm 1,242^{\#}$ \\
$\mathrm{dP} / \mathrm{dt}_{\text {max }}(\mathrm{mmHg} / \mathrm{s})$ &
\end{tabular}

HR- heart rate; SBP- systolic blood pressure; DBP- diastolic blood pressure; LVEDP - left ventricular end-diastolic pressure; $\mathrm{dP} / \mathrm{dt}_{\max }-$ maximal value of the $1^{\text {st }}$ temporal derivative of the ventricular pressure; \#- $\mathrm{p}<0,05$; ns- $\mathrm{p}>0,05$; *- the elevation occurred in all dogs.

of the individual data of this variable (fig. 2) enabled us to verify that, unexpectedly, and on a significant number of occasions ( 6 dogs), the values of the $\mathrm{dP} / \mathrm{dtmax}$ decreased following the elevation of the ventricular filling pressure.

\section{Discussion}

The increased values of $\mathrm{dP} / \mathrm{dt}$ noted in this study are in accordance with previously reported data, when we induced similar ventricular stretching in isolated canine hearts perfused with the blood of another dog ${ }^{15}$. The decreased values of $\mathrm{dP} / \mathrm{dt}$ observed in the present study were completely unexpected, considering the previous experiment. In the preparation of isolated heart, the ventricular expansion was followed by an increase in the values of $\mathrm{dP} / \mathrm{dt}$ in all the experiments ${ }^{15}$.

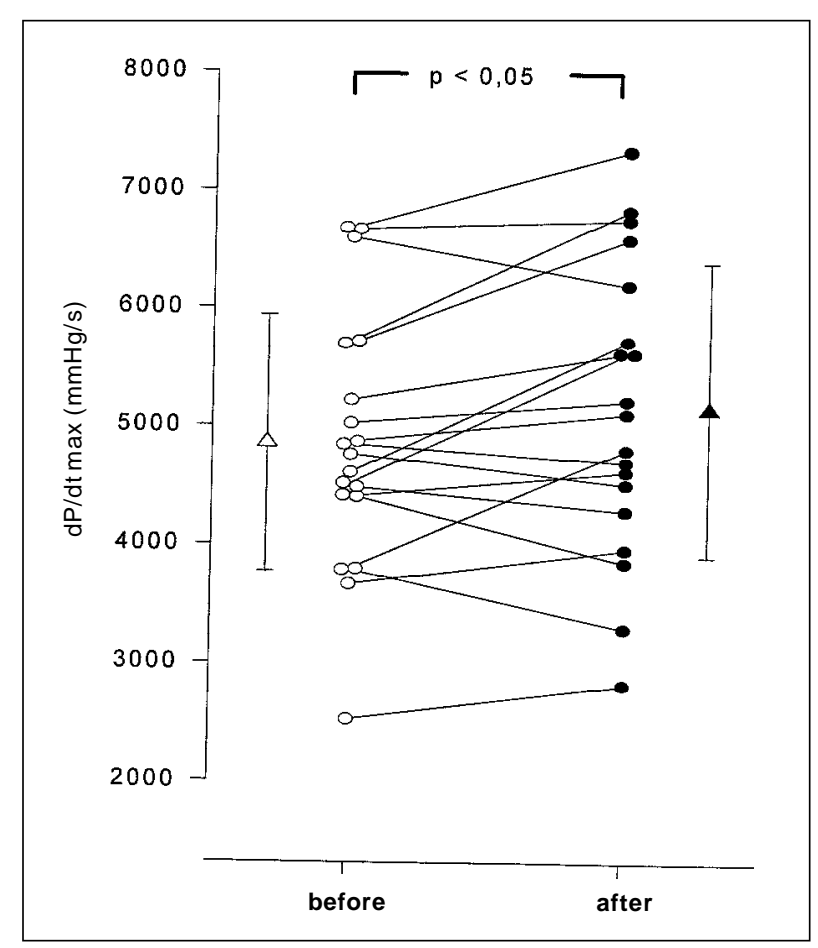

Fig. 2 - Individual values of the $1^{\text {st }}$ temporal derivative of the ventricular pressure $(\mathrm{dP} / \mathrm{dt})$ before and after the elevation of the left ventricular end-diastolic pressure.
In this study, the fact that the values of $\mathrm{dP} / \mathrm{dtmax}$ might have been influenced by the increase of blood pressure (BP), changes in the viscoelasticity of the myocardium and the Frank-Starling mechanism must be taken into account.

The increase of the aortic pressure could affect the values of $\mathrm{dP} / \mathrm{dt}$, inducing variations in the afterload ${ }^{8,23}$, in the perfusion pressure and in the coronary flow ${ }^{24-27}$. A series of publications ${ }^{3,7,8,23}$ report that the maximal values of $\mathrm{dP} / \mathrm{dt}$ are directly proportional to the levels of BP; others ${ }^{9,28,29}$, however, suggest that the aortic pressure has no influence on the $\mathrm{dP} / \mathrm{dt}$. The great variability of the models and the investigational protocols employed in these studies may be considered the determining factor of the controversial results. The authors who assessed the relationship between these 2 variables considered that, during oscillations of $\mathrm{BP}$, the values of $\mathrm{dP} / \mathrm{dt}$ may be modified as a result of variations in the afterload or in the coronary perfusion. Studies conducted in our laboratory ${ }^{29-31}$, whose methods were similar to those used in the present study, showed that, in the experimental conditions that we used, the sudden increase in the aortic pressure did not affect the values of $\mathrm{dP} / \mathrm{dtmax}$.

Another phenomenon that must be considered as a factor that might affect the ventricular function when BP is abruptly increased is the Anrep effect. The current concept about the Anrep effect is that, after a sudden increase in BP, a transient decrease of the inotropic capacity of the heart is observed, due to subendocardial ischemia. As a result of an autoregulatory vasodilation ${ }^{15,32,33}$, the perfusion of the heart is promptly restored, allowing the recovery of the inotropic capacity of the myocardium. As we performed the assessments of $\mathrm{dP} / \mathrm{dtmax}$ a few seconds after the heart load (preload and afterload) underwent variation, there is a possibility that the Anrep effect might be responsible for the decrease in the values of $\mathrm{dP} / \mathrm{dtmax}$ observed in some dogs in our study; that is, the evaluation of the $\mathrm{dP} / \mathrm{dt}$ may have occurred during a period when a transient myocardial ischemia was taking place. In addition, some authors ${ }^{34-36}$ noted a worsening of the myocardial perfusion as a result of the elevation of the diastolic pressure in the left ventricular cavity. This was also a consequence of the collapse of the subendocardial coronary vessels. The abnormal myocardial perfusion is likely to be the mechanism accounting for the decrease in the values of $\mathrm{dP} / \mathrm{dt}$ noted in some experiments.

Considering the characteristics of our protocol, another aspect to be considered is the viscoelasticity of the myocardium ${ }^{12,37-39}$. The viscoelastic component of the cardiac muscle confers resistance against the acute alterations in the muscular length ${ }^{37,38,40}$. This resistance depends on the rate of stretching and on the initial muscle length ${ }^{40-42}$. Thus, LeWinter et al ${ }^{37}$ noted that, to obtain the same value of LVEDP, the greatest dilation of the LV was seen when the maneuver of increasing the diastolic pressure was done slowly. In our study, it is not possible to determine precisely the influence of viscoelasticity in our results. However, if we consider that these factors would likely have influenced our 
results, this would be towards limiting the magnitude of ventricular dilation, probably decreasing the effects of the Frank-Starling mechanism.

The main effect of the volume infusion maneuver performed in our study was the improvement of the ventricular performance as a result of the Frank-Starling mechanism. Improvement of the ventricular performance is currently considered a result of the contributing physical factors and of factors that alter the intensity with which the contraction is activated ${ }^{12-15,17,43,44}$. The physical factors are related to the spatial disposition of the myofilaments, that is, myocardial stretching provides an increased spatial interaction between the myofilaments, increasing the number of active links between myosin and actin, and eventually improving the ventricular performance. The factors that activate contraction are related to myocardial contractility. It has been demonstrated that myocardial stretching increases the transarco- lemmal inflow of calcium ${ }^{4446}$, intensifies the release of calcium by the sarcoplasmic reticulum ${ }^{13,47,48}$ and increases the affinity of troponin $\mathrm{C}$ for calcium ${ }^{49-52}$. It is believed that the main factor that contributes to the improvement of the ventricular performance as a result of stretching is the improved myocardial contractility ${ }^{13,49,53}$. Thus, our findings of increased values of $\mathrm{dP} / \mathrm{dtmax}$ as a result of the elevation of the left ventricular diastolic pressure are likely to be a spontaneous result of the intensification of the process by which contraction is activated. If this statement is correct, the current focus on the relationship between preload and $\mathrm{dP} / \mathrm{dt}$, which considers the modifications due to stretching inadequate signs of deviations of the contractile state, will no longer prevail. Rather, the oscillations of dP/dt occurring in these circumstances may indicate the degree to which the contraction is activated secondary to the mobilization of factors that intervene in the kinetics of calcium.

\section{References}

1. Reeves TJ, Hefner LL, Jones WB, Coghlan C, Prieto G, Carroll J. The hemodynamic determinants of the rate of change in pressure in the left ventricle during isometric contraction. Am Heart J 1960; 60: 745-61.

2. Gleason WL, Braunwald E. Studies on the first derivative of the ventricular pressure pulse in man. J Clin Invest 1962; 41: 80-91.

3. Furnival CM, Linden RJ, Snow HM. Inotropic changes in the left ventricle: the effect of changes in heart rate, aortic pressure and end-diastolic pressure. J Physiol 1970; 211: 359-87.

4. Barnes GE, Bishop VS, Horwitz LD, Kaspar RL. The maximum derivatives of left ventricular pressure and transverse internal diameter as indices of the inotropic state of the left ventricle in conscious dogs. J Physiol 1973; 235: 571-90.

5. Braunwald E. Assessment of cardiac function. In: Braunwald E. A Textbook of Cardiovascular Medicine, $4^{\text {th }}$ ed., Philadelphia: WB Saunders, 1992: 419-43.

6. Mason DT. Usefulness and limitations of the rate of rise of intraventricular pressure $(\mathrm{dP} / \mathrm{dt})$ in the evaluation of myocardial contractility in man. Am J Cardiol 1969; 23: 516-27.

7. Van Den Bos GC, Elzinga G, Westerhof N, Noble MIM. Problems in the use of indices of myocardial contractility. Cardiovasc Res 1973; 7: 834-48.

8. Henning RJ, Levy MN. Effects of autonomic nerve stimulation, asynchrony, and load on $\mathrm{dP} / \mathrm{dt}_{\max }$ and on $\mathrm{dP} / \mathrm{dt}_{\min }$. Am J Physiol 1991; 260: H1290-8.

9. Mahler F, Ross J Jr, O'Rourke RA, Covell JW. Effects of changes in preload, afterload and inotropic state on ejection and isovolumic phase measures of contractility in the conscious dog. Am J Cardiol 1975; 35: 626-34.

10. Konishi T, Nakamura Y, Kato I, Kawai C. Dependence of peak dP/dt and mean ejection rate on load and effect of inotropic agents on the relationship between peak $\mathrm{dP} / \mathrm{dt}$ and left ventricular developed pressure-assessed in the isolated working rat heart and cardiac muscles. Int J Cardiol 1992; 35: 333-41.

11. Wüsten B, Flameng W, Winkler B, Schaper W. Role of cardiac contractility in hypertrophy from chronic volume loading. Cardiovasc Res 1977; 11: 132-40.

12. Parmley WW, Chuck L. Length-dependent changes in myocardial contractile state. Am J Physiol 1973; 224: 1195-9.

13. Fabiato A, Fabiato F. Dependence of the contractile activation of skinned cardiac cells on the sarcomere length. Nature $1975 ; 256$ : 54-6.

14. Allen DG, Kurihara $S$. The effects of muscle length on intracellular calcium transients in mammalian cardiac muscle. J Physiol 1982; 327: 79-94.

15. Tucci PJF, Bregagnollo EA, Spadaro J, Cicogna AC, Ribeiro MCL. Length dependence of activation studied in the isovolumic blood-perfused dog heart. Circ Res 1984; 55: 59-66.

16. Kentish JC, ter Keurs HEDJ, Ricciardi L, Bucx JJJ, Noble MIM. Comparison between the sarcomere length-force relations of intact and skinned trabeculae from rat right ventricle. Influence of calcium concentrations on these relations. Circ Res 1986; 58: 755-68.

17. Lew WYW. Time-dependent increase in left ventricular contractility following acute volume loading in the dog. Circ Res 1988; 63: 635-47.

18. Wallace AG, Skinner NS Jr, Mitchell JH. Hemodynamic determinants of the maximal rate of rise of left ventricular pressure. Am J Physiol 1963; 205: 30-6.
19. Mason DT, Braunwald E, Covell JW, Sonnenblick EH, Ross J Jr. Assessment of cardiac contractility. The relation between the rate of pressure rise and ventricular pressure during isovolumic systole. Circulation 1971; 44: 47-58.

20. Barnes GE, Horwitz LD, Bishop VS. Reliability of the maximum derivatives of left ventricular pressure and internal diameter as indices of the inotropic state of the depressed myocardium. Cardiovasc Res 1979; 13: 652-62.

21. Grossman W, Haynes F, Paraskos JA, Saltz S, Dalen JE, Dexter L. Alterations in preload and myocardial mechanics in the dog and in man. Circ Res 1972; 31: 83-94.

22. Noble MIM, Wyler J, MilneENC, TrenchardD, Guz A. Effect of changes in heart rate on left ventricular performance in conscious dogs. Circ Res 1969; 24: 285-95.

23. Scheufler K, Opitz H, Vogt H. Afterload dependence of cardiac contraction parameters. Biomed Biochim Acta 1989; 48: S408-11.

24. Arnold G, Kosche F, Miessner E, Neitzert A, Lochner W. The importance of the perfusion pressure in the coronary arteries for the contractility and the oxygen consumption of the heart. Pflügers Arch 1968; 299: 339-56.

25. Miller WP, Shimamoto N, Nellis SH, Liedtke AJ. Coronary hyperperfusion and myocardial metabolism in isolated and intact hearts. Am J Physiol 1987; 253: H1271-8.

26. Kitakaze M, Marban E. Cellular mechanism of the modulation of contractile function by coronary perfusion pressure in ferret hearts. J Physiol 1989; 414: 455-72.

27. Schipke JD, Stocks I, Sunderdiek U, Arnold G. Effect of changes in aortic pressure and in coronary arterial pressure on left ventricular geometry and function. Anrep vs. gardenhose effect. Basic Res Cardiol 1993; 88: 621-37.

28. Bugge-Asperheim B, Kiil F. Preload, contractility, and afterload as determinants of stroke volume during elevation of aortic blood pressure in dogs. Cardiovasc Res 1973; 7: 528-41.

29. Bregagnollo EA, Matsubara BB, Padovani C, Tucci PJF. Influência da elevação transitória e da elevação sustentada da pressão arterial sobre a primeira derivada temporal da pressão ventricular. Arq Bras Cardiol 1992; 58: 437-43.

30. Fioretto JR, Okoshi K, Tucci PJF. Influência da elevação sustentada da pressão arterial sobre a dP/dt do ventrículo esquerdo mantendo-se constante a pressão diastólica do ventrículo esquerdo. Arq Bras Cardiol 1996; 67: 159-64.

31. Fioretto JR, Okoshi MP, Okoshi K, et al. The rate of force generation by the myocardium is not influenced by afterload. Brazilian J Med Biol Res 1997; 30: 1471-7.

32. Monroe RG, Gamble WJ, LaFarge CG, et al. The Anrep effect reconsidered. J Clin Invest 1972; 51: 2573-83.

33. Vatner SF, Monroe RG, McRitchie RJ. Effects of anesthesia, tachycardia, and autonomic blockade on the Anrep effect in intact dogs. Am J Physiol 1974; 226 : 1450-6.

34. Dunn RB, Griggs DM Jr. Ventricular filling pressure as a determinant of coronary blood flow during ischemia. Am J Physiol 1983; 244: H429-36.

35. Aversano T, Klocke FJ, Mates RE, Canty JM Jr. Preload-induced alterations in capacitance-free diastolic pressure-flow relationships. Am J Physiol 1984; 246 : H410-7. 
36. Jeremy RW, Hughes CF, Fletcher PJ. Effects of left ventricular diastolic pressure on the pressure-flow relation of the coronary circulation during physiological vasodilatation. Cardiovasc Res 1986; 20: 922-30.

37. LeWinter MM, Engler R, Pavelec RS. Time-dependent shifts of the left ventricular diastolic filling relationship in conscious dogs. Circ Res 1979; 45: 641-53.

38. Way B, Victory J, LeWinter MM, et al. Hysteresis of left ventricular end ejection pressure-dimension relations after acute pressure loading in the intact canine heart. Cardiovasc Res 1986; 20: 490-7.

39. De Tombe PP, ter Keurs HEDJ. An internal viscous element limits unloaded velocity of sarcomere shortening in rat myocardium. J Physiol 1992; 454: 619-42.

40. Pouleur H, Karliner JS, LeWinter MM, Covell JW. Diastolic viscous properties of the intact canine left ventricle. Circ Res 1979; 45: 410-9.

41. Noble MIM. The diastolic viscous properties of cat papillary muscle. Circ Res 1977; 40: 288-92

42. Hoit BD, LeWinter M, Lew WYW. Independent influence of left atrial pressure on regional peak lengthening rates. Am J Physiol 1990; 259: H480-7.

43. Jewell BR. A reexamination of the influence of muscle length on myocardial performance. Circ Res 1977; 40: 221-30.

44. Allen DG, Kentish JC. The cellular basis of the length-tension relation in cardiac muscle. J Mol Cell Cardiol 1985; 17: 821-40.
45. Allen DG. On the relationship between action potential duration and tension in cat papillary muscle. Cardiovasc Res 1977; 11:210-8.

46. Lakatta EG, Jewell BR. Length-dependent activation. Its effect on the lengthtension relation in cat ventricular muscle. Circ Res 1977; 40: 251-7.

47. Ridgway EB, Gordon AM. Muscle activation: effects of small length changes on calcium release in single fibers. Science 1975; 189: 881-4.

48. Taylor SR, Rüdel R, Blinks JR. Calcium transients in amphibian muscle. Fed Proc 1975; 34: 1379-81.

49. Hibberd MG, Jewell BR. Calcium and length-dependent force production in rat ventricular muscle. J Physiol 1982; 329: 527-39.

50. Babu A, Sonnenblick E, Gulati J. Molecular basis for the influence of muscle length on myocardial performance. Science 1988; 240: 74-6.

51. Kentish JC. The length-tension relation in the myocardium and its cellular basis. Heart Failure 1988; 4: 125-36.

52. Gamble J, Taylor PB, Kenno KA. Myocardial stretch alters twitch characteristics and $\mathrm{Ca}^{2+}$ loading of sarcoplasmic reticulum in rat ventricular muscle. Cardiovasc Res 1992; 26: 865-70.

53. Lakatta EG. Starling's law of the heart is explained by an intimate interaction of muscle length and myofilament calcium activation. J Am Coll Cardiol 1987; 10: 1157-64. 